\title{
CHARACTERISTICS AND LABORATORY FREEZE-THAW TEST OF SALINE SOIL IN WEST JILIN, CHINA
}

\author{
BAO, S. ${ }^{1,2}-$ WANG, Q. ${ }^{3}-$ BIAN, J. ${ }^{2 *}-$ LI, M. ${ }^{1}-$ WANG, Z. ${ }^{4}$ \\ ${ }^{I}$ College of Civil Engineering, Jilin Jianzhu University \\ Changchun 130000, China \\ (e-mail: baoshuochao@126.com; limingjljz@126.com) \\ ${ }^{2}$ College of Environment and Resources, Jilin University \\ Changchun 130026, China \\ ${ }^{3}$ College of Construction Engineering, Jilin University \\ Changchun 130026, China \\ (e-mail:wangqing@jlu.edu.com) \\ ${ }^{4}$ Jilin Team of Geological Survey Center of China, Building Materials Industry \\ Changchun 130000, China \\ (e-mail:355899156@qq.com) \\ *Corresponding author \\ e-mail: bianjianmin@126.com \\ (Received $24^{\text {th }}$ Jun 2017; accepted $2^{\text {nd }}$ Nov 2017)
}

\begin{abstract}
For the purpose of investigating the characteristic and material composition of saline soil in western Jilin, China the saline soil distribution area of Da'an in west Jilin Province was sampled during a site investigation, after which the fundamental properties of the soil were investigated in the laboratory. The soluble salt ranged from $0.28 \%$ to $0.60 \%$, decreasing with depth from 0 to $40 \mathrm{~cm}$ blow the surface. Conversely, the moisture content increased with increasing depth, but showed little change beneath 40 $\mathrm{cm}$. An indoor freeze-thaw simulation test revealed that the moisture migrated under the temperature gradient, while the salinity migrated upwards under the combined action of the temperature gradient and concentration gradient, with the optimum degree of compaction for salinity migration being $90 \%$. Following freezing, the inside structure became looser, and this phenomenon was more obvious when the temperature was lower. The research provided the basis for prevention of the secondary salinization and frost heaving the disease of saline soil in western Jilin province.
\end{abstract}

Keywords: saline soil, freeze-thaw test, water migration, salt migration, microstructure

\section{Introduction}

Saline soil is a kind of special soil whose salt content is more than $0.3 \%$ (Chai, 1983). Saline soil is widely distributed on the Earth's surface, resulting in expansion, dissolution or corrosion characteristics that can cause serious damage to agricultural and architectural environment (Wang et al., 2011; Hejazi et al., 2017). Some damage to roads in saline soil areas are related to the particular characteristics of saline soil. The formation of saline soil occurs in response to evaporation caused by underground water migration and the hot-dry climate (Kovda, 1958; Blaser and Schere, 1973; Kovda and Szabolcs, 1979). Upward migration of salinity with water migration is the main form of salinity accumulation in soil (Lv et al., 1999). Moreover, changes in temperature affect the migration of salinity in saline soil (Bear and Gilma, 1995), with saline soil being distributed in cold regions, especially those subjected to seasonal freezing, showing salt expansion damage due to 
variations in water, salinity, temperature and stress (Deng and Zhou, 2009; Zhang et al. 2010). Because salt in the soil has a different impact on the freezing point (Ma et al., 2016; Bing et al., 2016), the experiment of salt centent and freeze-thaw characteristic is necessary.

Western Jilin Province is a typical seasonal frozen soil distribution area of northeast China that has large amounts of saline soil. This region has severe cold winters and torrid summers, with low annual precipitation. The rainy season is from June to August, while spring and autumn are dry and windy. Due to the strong evaporation effect of the earth's surface, salinity in soil easily gathers on the surface and forms saline soil (Zhang, 2010; Hashemi, 2017). Furthermore, water migration during the freezing process in winter brings salinity to the freezing front, and salinity again accumulates during spring due to surface evaporation, aggravating the degree of soil salinity. Soil salinization not only brings serious harm to agricultural production, but also leads to damage to engineering projects such as frost heave and differential settlement of highways. Therefore, it is essential to investigate the characteristics of saline soil in western Jilin (Radan et al., 2017).

In this study, soil samples were collected from Da'an in Jilin Province and subjected to a series of laboratory and freeze-thaw simulation tests to investigate their properties. Scanning electron microscopy (SEM) was also used to examine the microstructure of the different samples to evaluate the effects of the freezing process.

\section{Materials and Methods}

\section{Soil materials}

Soil samples were collected from the Da'an area of Jilin Province during spring. A total of six samples were collected, one each from depths of $20 \mathrm{~cm}, 30 \mathrm{~cm}, 40 \mathrm{~cm}, 50 \mathrm{~cm}$, $70 \mathrm{~cm}$ and $100 \mathrm{~cm}$. Soil samples were digged from the nature soil layers below the ground. The surface of the field was dry and gray-white because of the massive crystals of soluble salt, while the underground soils were wet and black-brown or gray.

Soils were analyzed (Wang et al., 2013; Talitha et al., 2013) for particle composition, moisture content and salinity content (Table 1).

Table 1. Basic characteristics of soil samples

\begin{tabular}{|c|c|c|c|c|c|c|c|c|c|}
\hline \multirow{2}{*}{$\begin{array}{l}\text { Depth of } \\
\text { soil } \\
\text { samples/ } \\
\text { cm } \\
\end{array}$} & \multirow[b]{2}{*}{$\begin{array}{c}\text { Density/ } \\
\mathbf{g} / \mathrm{cm}^{3}\end{array}$} & \multicolumn{3}{|c|}{ Particles mass fraction $/ \%$} & \multirow[b]{2}{*}{$\begin{array}{c}\text { Moisture } \\
\text { content/ } \\
\%\end{array}$} & \multirow[b]{2}{*}{$\begin{array}{c}\text { Liquid limit } \\
\text { moisture } \\
\text { content } / \%\end{array}$} & \multirow{2}{*}{\begin{tabular}{|c} 
Plastic \\
limit \\
moisture \\
content $/ \%$
\end{tabular}} & \multirow[b]{2}{*}{ Ip } & \multirow{2}{*}{$\begin{array}{c}\begin{array}{c}\text { Soluble } \\
\text { salt } \\
\text { content } \\
1 \%\end{array} \\
\end{array}$} \\
\hline & & $\begin{array}{c}\text { Sand } \\
2- \\
0.075 \mathrm{~mm}\end{array}$ & $\begin{array}{c}\text { Silt } \\
0.075- \\
0.005 \mathrm{~mm}\end{array}$ & $\begin{array}{c}\text { Clay } \\
<0.005\end{array}$ & & & & & \\
\hline 20 & 1.69 & 9.6 & 59.2 & 31.2 & 12.51 & 32.00 & 21.40 & 10.60 & 0.6 \\
\hline 30 & 1.79 & 5.5 & 52.8 & 41.7 & 19.79 & 35.10 & 20.00 & 15.10 & 0.55 \\
\hline 40 & 1.66 & 9.5 & 53.6 & 36.9 & 20.68 & 36.00 & 22.10 & 13.90 & 0.49 \\
\hline 50 & 1.79 & 4.6 & 50.6 & 44.8 & 20.55 & 35.80 & 20.40 & 15.40 & 0.35 \\
\hline 70 & 1.81 & 4.1 & 52.0 & 43.9 & 20.77 & 34.50 & 21.60 & 12.90 & 0.28 \\
\hline 100 & 1.82 & 4.6 & 52.7 & 42.7 & 18.14 & 34.10 & 21.00 & 13.10 & 0.29 \\
\hline
\end{tabular}


Additionally, the mineral composition of samples from $20 \mathrm{~cm}$ and $100 \mathrm{~cm}$ were analyzed by X-ray diffraction (XRD) (Table 2). The results revealed that the clay content of the soil samples ranged from $31.2 \%$ to $44.8 \%$. The natural moisture content of samples collected from 0 to $40 \mathrm{~cm}$ increased with depth, but little change in moisture was observed below $40 \mathrm{~cm}$. The soluble salt content decreased with increasing depth. Based on a $0.3 \%$ soluble salt content indicating saline soils, the soil was saline soil at above $50 \mathrm{~cm}$ in the research area. The soil was primary mineral based, and included quartz, alkali-feldspar and plagioclase (Vazdani et al., 2017).

Table 2. Mineral composition of soil samples

\begin{tabular}{c|c|c|c|c|c|c|c|c}
\hline \multirow{2}{*}{$\begin{array}{c}\text { Depth of soil } \\
\text { samples/cm }\end{array}$} & \multicolumn{8}{c}{ Percentage composition of minerals /\% } \\
\cline { 2 - 9 } & fs & Q & PI & Cc & I/S & K & I & Am \\
\hline 20 & 20 & 39 & 21 & 6 & 6 & 4 & 4 & \\
100 & 11 & 41 & 21 & 11 & 7 & 4 & 4 & 1 \\
\hline
\end{tabular}

fs: alkali feldspar, Q: quartz, Pl: plagioclase, Cc: calcite, I/S: illite-smectite mixed layer, K: kaolinite,

I: illite, Am: hornblende

\section{Methods}

A temperature-controlled capillary water tester was designed for this study to simulate freeze-thaw conditions in the field. The equipment was composed of three temperature-controlled, compartments that could be controlled separately. Each compartment had a capacity of $50 \mathrm{~cm}$ of soil, and there was a hole between the adjacent compartments so the soil samples could be compacted into a tube stand in the device that ran through the three compartments. The photo and diagram of the tester are shown in Fig. 1. and Fig. 2.

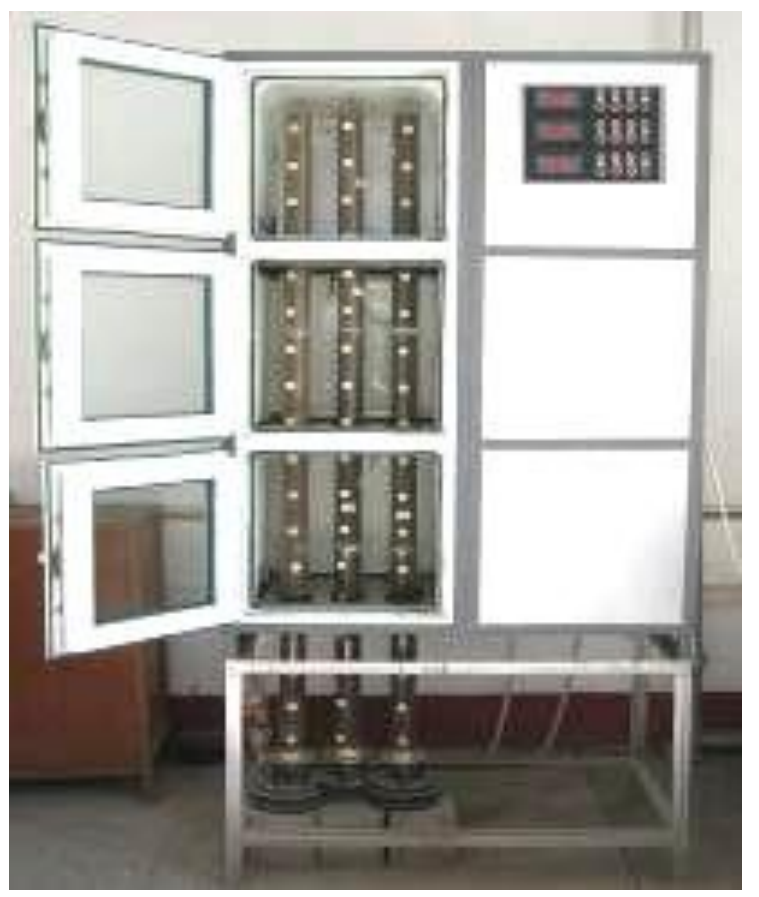

Figure 1. Temperature-controlled capillary water tester 


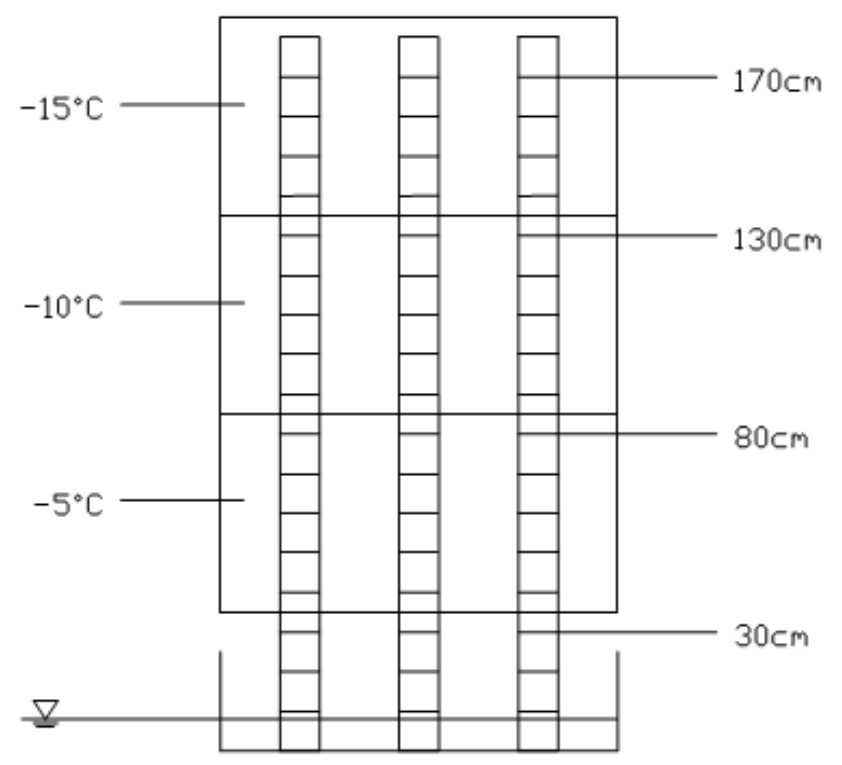

Figure 2. Diagram of the temperature-controlled capillary water tester

After field monitoring of the winter ground temperature in western Jilin, the temperature of the three compartments was set as $-5^{\circ} \mathrm{C},-10^{\circ} \mathrm{C}$, and $-15^{\circ} \mathrm{C}$. Soil collected from 20 to $30 \mathrm{~cm}$ was selected for the freeze-thaw simulation test. Briefly, the initial moisture content was adjusted to $18 \%$ to simulate the native state, after which the soil was compacted into three $180 \mathrm{~cm}$ tubes with a compaction degree of $85 \%, 90 \%$ and $95 \%$. The bottom $30 \mathrm{~cm}$ of the tubes were then placed in a water channel under room temperature.

During the first 2 days, the temperature was gradually reduced in the compartments until the pretest temperature was reached. The soil beneath the compartments was constantly maintained at an indoor temperature (approximately $18^{\circ} \mathrm{C}$ ). Normally winter lasts 4 months in study area, and the soil is frozen for 3 months in nature. Therefore, the freezing process lasted for 3 months, after which the soil was immediately sampled before thawing. Soil samples were collected from the tubes in $10 \mathrm{~cm}$ intervals, after which the moisture content was immediately measured. In addition, other soil samples were collected from each room and analyzed for salt content and microstructure.

\section{Results and Discussion}

\section{Change in moisture after freezing}

The moisture contents at different heights after freezing are shown in Fig. 3. There was little change in moisture observed with increasing height for all compactions, indicating little variation in the initial moisture content. However, the moisture contents increased slightly near the temperature dividing line (Xiao et al., 2017). As a result, a portion of the observed water migration was in response to the temperature gradient. This was mainly due to the temperature gradient causing film water to migrate in the soil, while capillary water did not migrate. Due to the temperature gradient, the original soil water potential balance was broken at a different position, resulting in migration of the water from unfrozen soil into frozen soil. This led to a redistribution of the moisture 
distribution. In this experiment, the moisture contents of unfrozen soil were lower than the initial content at $150 \mathrm{~cm}$, but the moisture contents of frozen soil were higher than the initial content, and the water migrated slightly at that position. Moreover, different degrees of water migration were observed at $50 \mathrm{~cm}$ and $100 \mathrm{~cm}$ due to the temperature gradient. However, the film water of soil in the same temperature-controlled compartment did not migrate because the temperatures were the same.

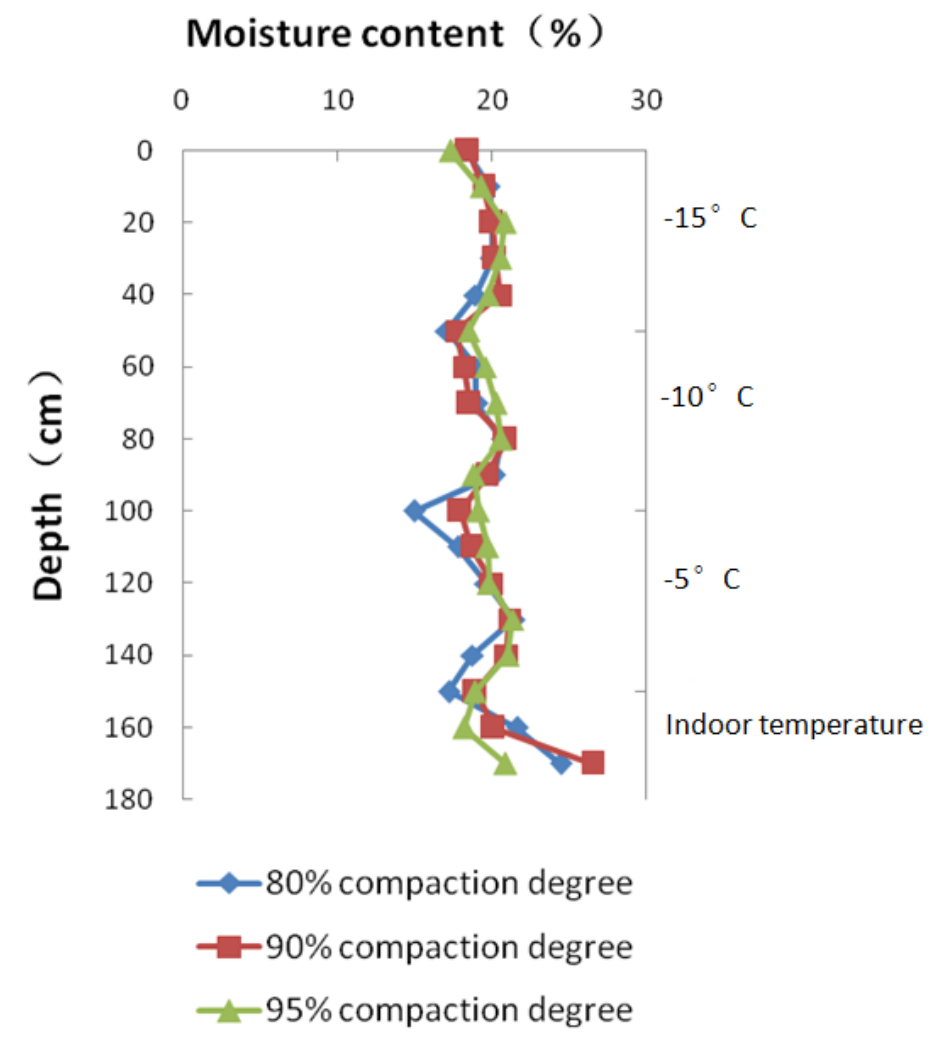

Figure 3. Relationship between moisture content and height

\section{Change in salinity after freezing}

The soluble salt contents of soil samples after freezing were tested by an oven drying method, and the variations in soluble salt contents with depth are shown in Fig. 4. The variations in salt content were similar between soil samples at compaction degrees of $85 \%$ and $90 \%$, with an increase occurring from 50 to $150 \mathrm{~cm}$, but little change from 10 to $50 \mathrm{~cm}$. The variation in salt content at $90 \%$ compaction differed, showing an increase, followed by a decrease and then another increase with depth. At this level of compaction, the changes in salt content occurred around $50 \mathrm{~cm}$ and $100 \mathrm{~cm}$, while the salinity migrated between $50 \mathrm{~cm}$ and $100 \mathrm{~cm}$. These findings indicate that the degree of soil compaction influenced the migration of salt with water, with the salt carried by water in the soil migrating effectively under high compaction, but being restricted above a threshold. In this study, $90 \%$ was found to be the optimum degree of compaction. 


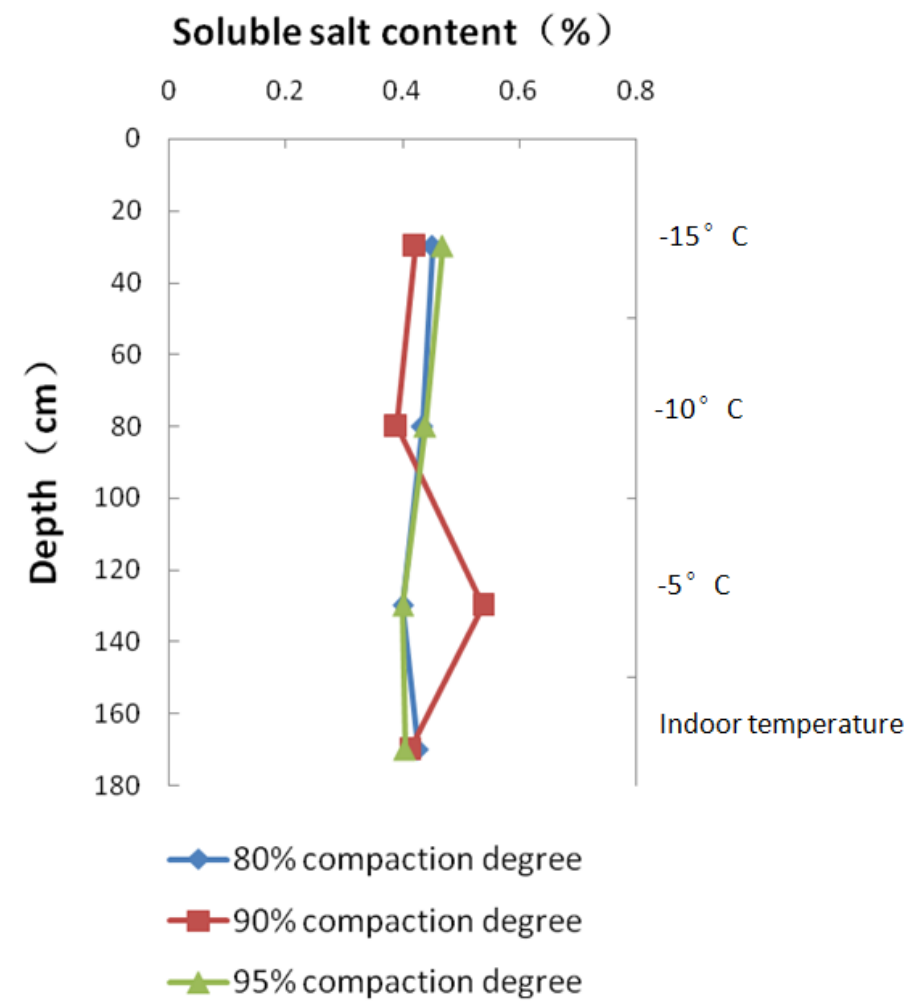

Figure 4. Relation curves of soluble salt content and height after freezing

The soluble salt content in the native state is shown in Fig. 5. The salt content obviously increased with depth, especially at $20-50 \mathrm{~cm}$. The salt migration trend was similar to that of the laboratory test, but more obvious. This is because salt migrates into soil via the surface over a long period when soil is in its native state.

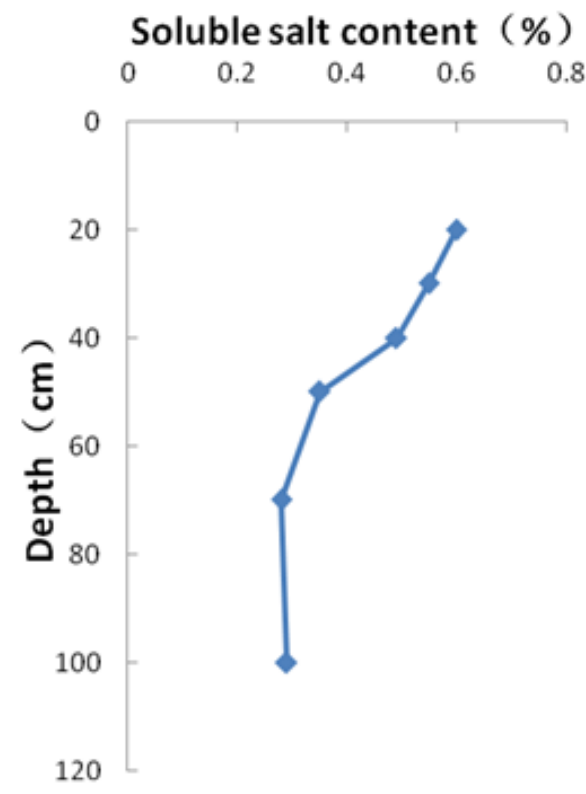

Figure 5. Relation curves of soluble salt content and height at native state 


\section{Changes in microstructure after freezing}

SEM was used to investigate the soil microstructure before and after freezing. During the test, liquid nitrogen was used to freeze the soil samples quickly to ensure that the water did not turn into amorphous ice and break the original microstructure. The ice in the soil was then sublimated in a low temperature vacuum apparatus and pumped out with a vacuum pump to ensure that the pores in the soil did not become deformed. Fig. 6 shows the SEM images of soil samples with an $85 \%, 90 \%$ and $95 \%$ compaction degree at different freezing temperatures, as well as the soil sample with a $95 \%$ compaction degree and normal temperature.

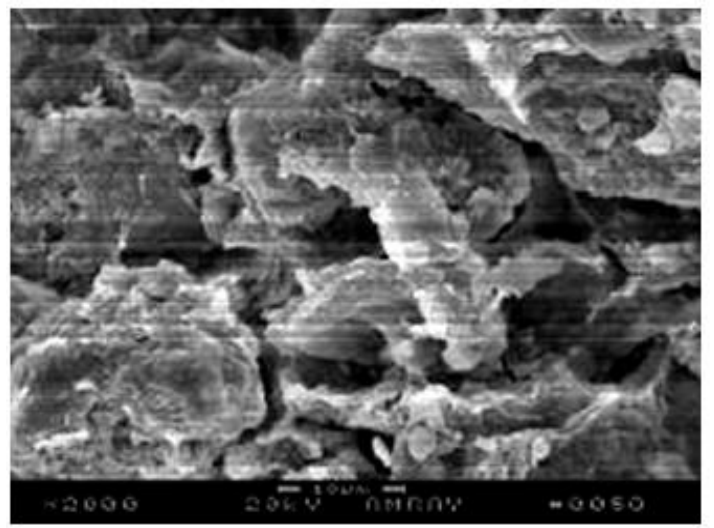

a. $85 \%$ compaction degree, $-5{ }^{\circ} \mathrm{C}$

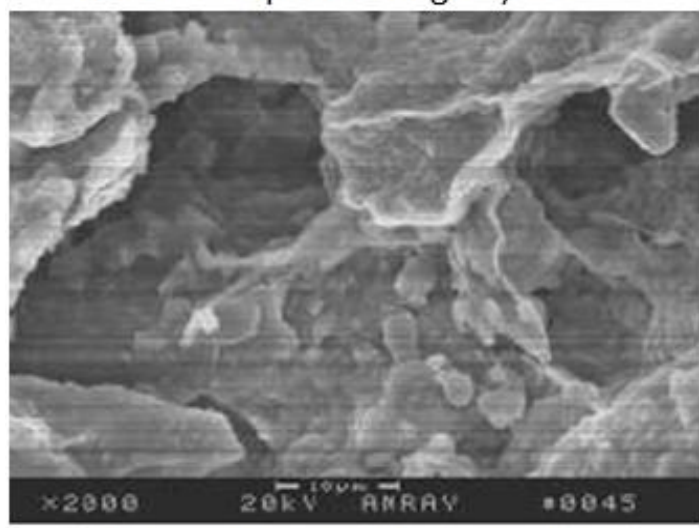

c. $85 \%$ compaction degree, $-15^{\circ} \mathrm{C}$

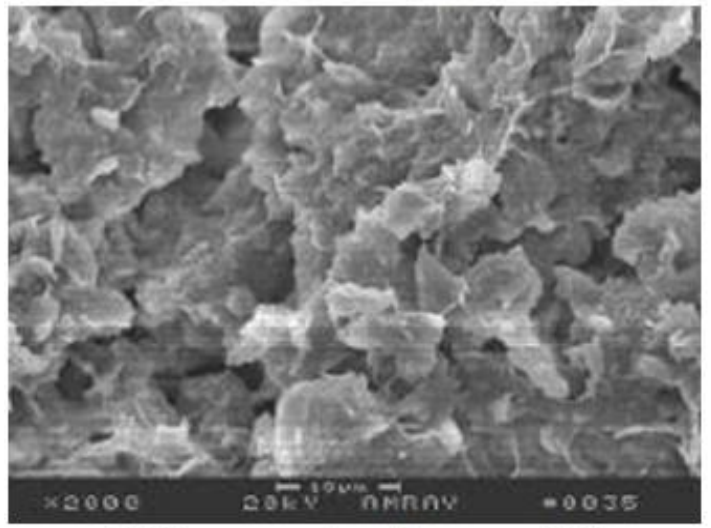

e. $90 \%$ compaction degree, $-10^{\circ} \mathrm{C}$

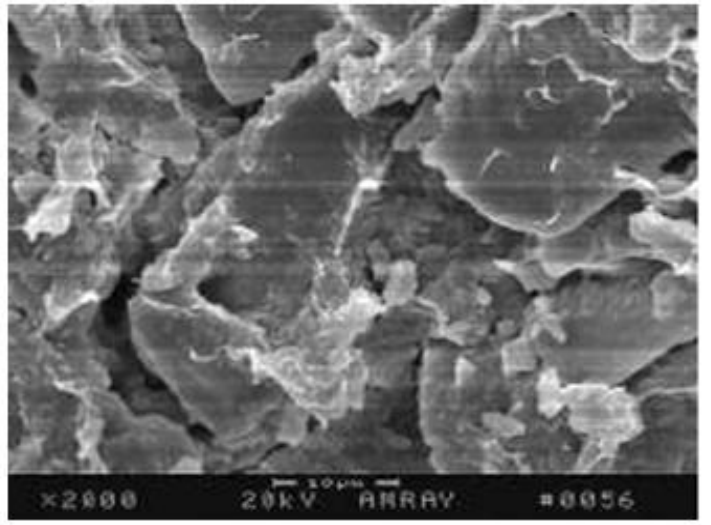

b. $85 \%$ compaction degree, $-10^{\circ} \mathrm{C}$

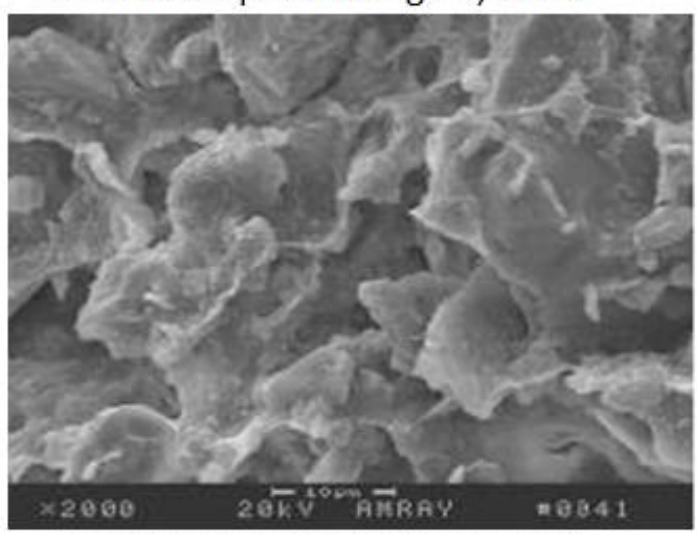

d. $90 \%$ compaction degree, $-5^{\circ} \mathrm{C}$

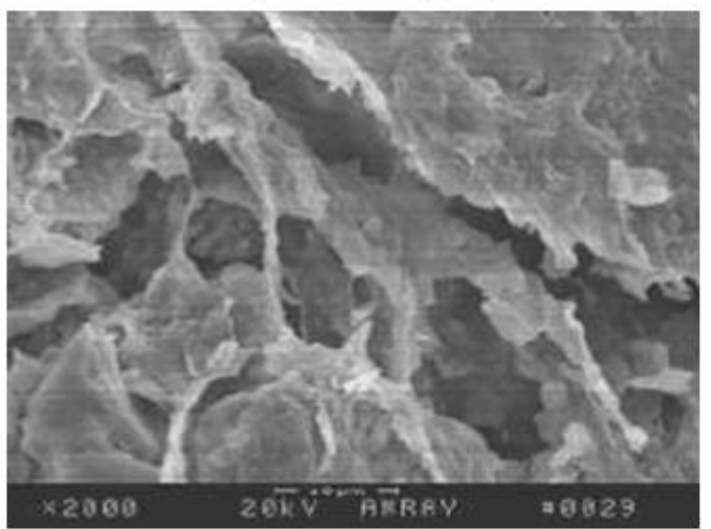

f. $90 \%$ compaction degree, $-15^{\circ} \mathrm{C}$ 


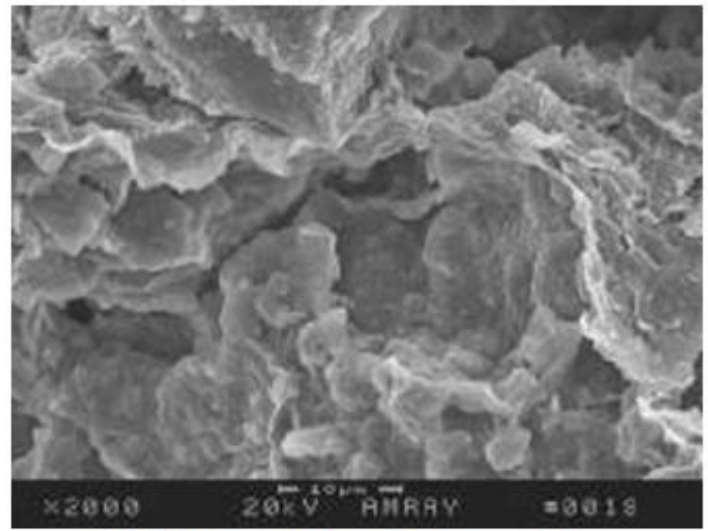

g. $95 \%$ compaction degree, $-5^{\circ} \mathrm{C}$

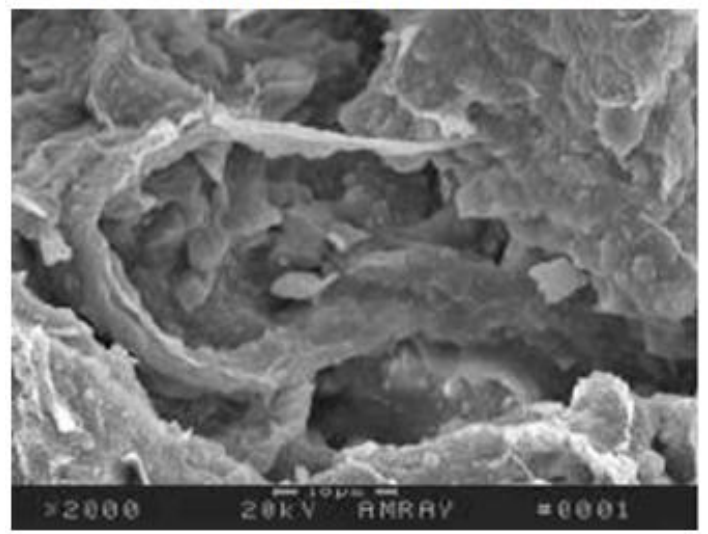

i. $95 \%$ compaction degree, $-15^{\circ} \mathrm{C}$

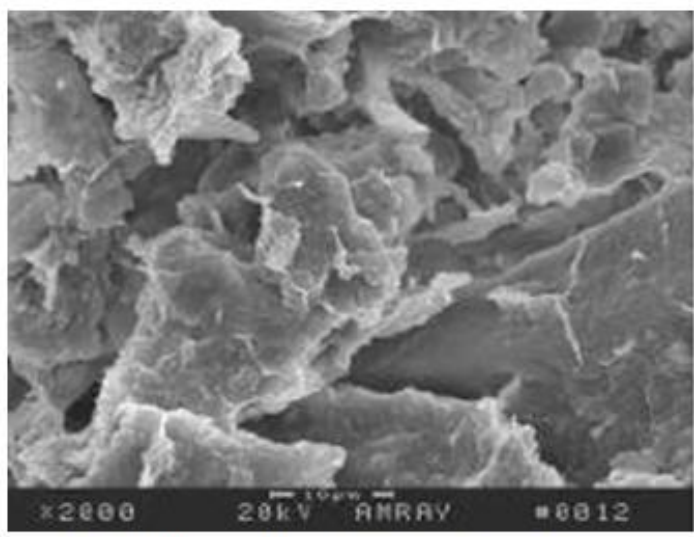

h. $95 \%$ compaction degree, $-10^{\circ} \mathrm{C}$

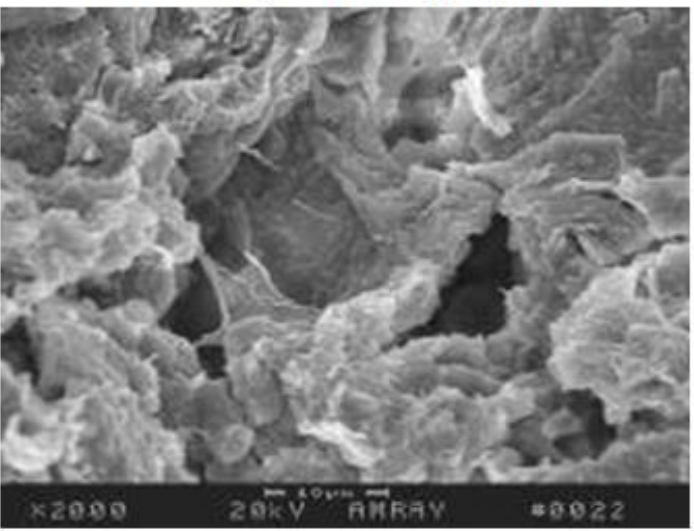

j. $95 \%$ compaction degree, normal temperature

Figure 6. SEM micrograph of soil samples indifferent freezing temperatures

As shown in Fig. 6., soil particles had a flocculence granular structure, with clay minerals primarily composed of illite and an illite-smectite mixed layer. In addition, there was a high volume of xenomorphic minerals with a poor degree of crystallinity. As a result, the clay contents and xenomorphic analysis indicate different regulation of the mineral contents (Table 1 and Table 2). The structures are primarily formed via cementation inosculation, the structure is loose and cracked, and salinity crystals are present in the soil pores.

Comparison of the SEM images at different temperatures revealed that changes in temperature not only affect the size of soil structural units and pores, but also influence the arrangement of soil structural units and pores (Zhang et al. 2017). Lower freezing temperatures are associated with looser soil structural units, while higher pore volume is associated with more obvious formation of seepage channels. This phenomenon is due to lowering of the freezing temperature (Wan et al, 2013; Yang et al., 2017), which results in water in the soil continually turning to ice, after which the ice crystals break the original structure and enlarge the pore volume. Moreover, the unfrozen water content decreases, and saline ions increase in solution. When the solution concentration exceeds the solubility of sodium bicarbonate, sodium bicarbonate crystal precipitates. As the temperature decreases, ice and salt crystals increase continually, causing the soil particles to be stretched and squeezed. This causes the distance between soil particles to 
increase and pore volumes to expand, leading to the soil structure becoming looser, large particles breaking into small particles, and the large soil particle content decreasing.

Comparison of the SEM images at different compaction degrees reveals that the particle content decreased most obviously at $90 \%$ compaction as the temperature decreased. As the compaction degree increased, the deformation of soil particles and pores were depressed to a certain extent. Additionally, increasing ice crystals and salt crystals can enlarge the pore diameters when the soil sample is loose; however, if the soil sample becomes excessively loose, the increasing ice crystals and salt crystals primarily fill the original pores. As the SEM results show, the deformation of the soil was greater at $90 \%$ compaction.

\section{Conclusion}

Investigation of saline soils by an indoor freezing-thaw simulation test revealed the following:

1. The soil in the research area is low liquid-limit clay. The moisture content of this soil decreases with increasing depth due to evaporation in shallow earth, but does not change greatly deeper down. Soil more than $50 \mathrm{~cm}$ underground is saline, which can cause damage to industry and agriculture.

2. The moisture and salt all shows migration during freezing progress. The water content only increased slightly with depth near the temperature dividing line. This phenomenon was caused by film water migration, not capillary movement of water. The salinity migrates upward with film water under the combined action of the temperature gradient and concentration gradient. This is one of the main reasons for the high soil salinity in western Jilin.

3. Salt migration is more obvious when the degree of compaction is larger; however, if soil is compacted too much, it will cause the soil particles to be too close together, limiting the migration of water and salt. The optimum degree of compaction for salt migration was $90 \%$ in the research area.

4. Due to the limitations of experiment, this paper only discussed the soil collected in spring, the following research will take more experiments of summer and autumn soil and investigate more characteristic of saline soil in western Jilin.

Acknowledgements. This work was supported by Scientific Research project of Jilin Province Department of Education (grant number: JJKH20170248KJ, JJKH20170255KJ) Jilin Province Science and Technology Development Projects (grant number: No. 20150623024TC-13), Natural Science Foundation of China (grant numbers: NO.41430642, NO.41372267).

\section{REFERENCES}

[1] Bear, J., Gilman, A. (1995): Migration of salts in the unsaturated zone caused by heating. - Transport in Porous Media 19(2): 139-156.

[2] Bing H., Zhao S., Du Y. (2016): Design and development of a test system for measuring ultrasonic wave of frozen soil. - Journal of Glaciology and Geocryology 38( 4): 937-942 (in Chinese)

[3] Blaser, H. D., Schere, O. J. (1973): Simultaneous transport of solutes and water under transient unsaturated flow conditions. - Water Resour. Res. 9: 975-986

[4] Chai, B. Z.(1983): Engineering properties of saline soil. - Geotechnical Investigation \& 
Surveying 6:12-14.

[5] Deng, Y. S., Zhou, C. L. (2009): Salt expansion and frost heave of sodium sulphate solution. - Journal of Glaciology and Geocryology 31(5): 920-924.

[6] Hashemi, N. (2017): Recognizing the potential of sustainable use of pasture resources in south Khorasan province with approch of carrying capacity. - Environment Ecosystem Science 1(2): 09-12.

[7] Hejazi, S. M., Lotfi, F., Fashandi, H., Alirezazadeh, A. (2017): Serishm: an eco-friendly and biodegradable flame retardant for fabrics. - Environment Ecosystem Science 1(2): 05-08.

[8] Kovda, V. A. (1958): The occurrence of saline soil and improvement. - Soils 3: 15-16

[9] Kovda, V. A., Szabolcs, I. (1979): Modelling of Soil Salinization and Alkalization. Agrokoemia es Talajtan, Budapest.

[10] Lv, D. Q., Wang, W. Y., Wang, Q. J. (1999): Transport of soil salt and water in processes of infiltrationand evaporation. - Research of Soil and Water conservation 6(2): 61-66.

[11] Ma, M., Bing, H., Li, G. Y. (2016): Experimental research on unfrozen water content of sodium sulphate saline soil. - Journal of Glaciology and Geocryoloy 38(4): 963-969. (in Chinese)

[12] Radan, A., Latifi, M., Moshtaghie, M., Ahmadi, M., Omidi, M. (2017): Determining the Sensitive Conservative Site in Kolah Ghazi National Park, Iran, In Order to Management Wildlife by Using GIS Software. - Environment Ecosystem Science 1(2): 13-15.

[13] Talitha, C. S., Martin, V. F., Michael, N. S. (2013): Evaluation of soil analytical methods for the characterization of alkaline technosols: I. moisture content, $\mathrm{pH}$, and electrical conductivity. - Journal of Soil and Sediments 13: 1141-1149.

[14] Vazdani, S., Sabzghabaei, G., Dashti, S., Cheraghi, M., Alizadeh, R., Hemmati, A. (2017): Fmea Techniques Used in Environmental Risk Assessment. - Environment Ecosystem Science 1(2): 16-18.

[15] Wan, X. S., Lai, Y. M. (2013): Experimental study of freezing temperature and salt crystal precipitation of sodium sulphate soulution and sodiumsulphate saline soil. - Chinese Journal of Geotechnical Engineering 35(11): 2090-2096.

[16] Wang, W. H., Wang, Q., Zhang, J., Chen, H. E. (2011): An experiment study of the fundamental property of the carbonate-saline soil in west of Jilin province. - Journal of Beijing University of Techology 37(2): 217-224. (in Chinese)

[17] Wang, Y. F., Tang, C. X,. Wu, J. J., Liu, X. M., Xu, J. M. (2013): Impact of organic matter addition on $\mathrm{pH}$ change of paddy soils. - Journal of Soil and Sediments 13: 12-23

[18] Xiao, H., Wang, M., Sheng, S. (2017): Spatial evolution of URNCL and response of ecological security: a case study on Foshan City. - Geology, Ecology, and Landscapes 1(3): 190-196.

[19] Yang, S., Li, J., Song, Y. (2017): Application of surfactant Tween 80 to enhance Fenton oxidation of polycyclic aromatic hydrocarbons (PAHs) in soil pre-treated with Fenton reagents. - Geology, Ecology, and Landscapes 1(3): 197-204.

[20] Zhang, J. (2010). Research on the dispersion mechanism of the dispersive seasonal frozen soil in the western of Jilin province. - Dissertation of Jilin University, Changchun. (in Chinese)

[21] Zhang, S. S., Xie, Y. L., Yang, X. H., Dai, Z. R. (2010): Research on microstructure of crude coarse grain saline soil under freezing and thawing cycles. - Rock and Soil Mechanics 31(1): 123-127. (in Chinese)

[22] Zhang, Z., Zhou, H. Qing, Q. (2017): Experimental study on porosity characteristic of loess under freezing-thawing cycle. - Journal of Jilin University (Earth Science Edition) 47(3):839-847. (in Chinese) 